\title{
Coccidial infections of goats in Selangor, Peninsular Malaysia
}

\begin{abstract}
Coccidial infections were studied in goats in the state of Selangor (peninsular Malaysia) during a 12-month period. The study included 10 smallholder farms on which kids were monitored for faecal oocyst counts from birth until 1-year old. Eimeria oocysts were found in $725(89 \%)$ of 815 faecal samples examined. Nine species of Eimeria were identified. The most prevalent were E. arloingi, found in $71 \%$ of the samples, E. ninakohlyakimovae $(67 \%)$, E. christenseni (63\%) and E. alijevi (61\%). The other species found were, E. hirci, E. jolchijevi, E. caprovina, E. caprina and E. pallida, present in 34, 2212,9 and $4 \%$ of the samples, respectively. Oocyst counts were significantly higher in animals of less than 4months old $(\mathrm{P}<0.05)$. High oocyst counts were mainly caused by non-pathogenic species. Poor hygienic conditions were found to be associated with a higher intensity of coccidial infections. Mortality rates in kids could not be related to the intensity of coccidial infections.
\end{abstract}

Keyword: Eimeria spp, Goat, Malaysia 